\title{
Optimization of the mechanical properties of abaca fibre-reinforced high impact polystyrene (HIPS) composites using Box-Behnken design of experiments
}

\begin{abstract}
Mechanical properties of polymer composites are influenced by many factors such as the types of fibres, the types of polymer matrix, the additives used and the adhesion between fibres and polymer matrix. To improve the interfacial adhesion between HIPS matrix and abaca fibres, a study of the optimum use of a coupling agent (MAH) and impact modifier is presented in this paper. Abaca fibre reinforced high impact polystyrene (HIPS) composites were produced with different fibre loadings (30, 40 and $50 \mathrm{wt} . \%)$, different compositions of coupling agent, maleic anhydride (MAH) (1, 2 and 3 wt.\%) and different compositions of impact-modifier (4, 5 and 6 wt.\%). A response surface methodology using Box-Behnken design was used in the design of experiments and analysis of results. Statistical analysis of mechanical properties gave very satisfactory model accuracy, because the coefficient of determinance was 0.9817 for impact strength, 0.9789 for tensile strength, 0.9672 for tensile modulus, 0.9700 for flexural strength, and 0.9747 for flexural modulus. In this study, a loading of abaca fibre of $36.76 \mathrm{wt} . \%$, maleic anhydride $3 \mathrm{wt} . \%$, and impact modifier $4 \mathrm{wt} \%$ led to optimum individual impact strength. On the other hand, optimum individual tensile strength and tensile modulus were achieved when the loading of abaca fibre was close to 40.76 wt.\%, maleic anhydride 3 wt. $\%$ and impact modifier 6 wt.\%, but the optimum individual flexural strength and flexural modulus were found when the loading abaca fibre was close to $40.03 \mathrm{wt} . \%$, maleic anhydride $3 \mathrm{wt} . \%$ and impact modifier $4 \mathrm{wt} . \%$.
\end{abstract}

Keyword: High impact polystyrene; Fibre reinforced; Impact modifiers 